\title{
Development of a Substitute Oil for Vipadikahara Grita Taila and It's Evaluation Against Vipadika Skin Disease (A Case Study)
}

\author{
H. G. S. P. Hewageegana ${ }^{1, ~ *}$, L A D M Arawwawala ${ }^{2}$, I. Dhammaratana ${ }^{3}$, H A S Ariyawansa ${ }^{1}$, \\ M H A Tissera ${ }^{4}$
}

${ }^{1}$ Institute of Indigenous Medicine, University of Colombo, Rajagiriya, Sri Lanka

${ }^{2}$ Industrial Technology Institute, Bauddhaloka Mawatha, Colombo, Sri Lanka

${ }^{3}$ Faculty of Humanities, University of Kelaniya, Kelaniya, Sri Lanka

${ }^{4}$ Wickramarachchi Ayurveda College, University of Kelaniya, Yakkala, Sri Lanka

\section{Email address:}

sujathahgsp@yahoo.com (H.G.S.P. Hewageegana)

\section{To cite this article:}

H. G. S. P. Hewageegana, L A D M Arawwawala, I. Dhammarathana, H A S Ariyawansa, M H A Tissera. Development of a Substitute Oil for Vipadikahara Grita Taila and It's Evaluation Against Vipadika Skin Disease (A Case Study). American Journal of Clinical and Experimental Medicine. Vol. 3, No. 5, 2015, pp. 306-309. doi: 10.11648/j.ajcem.20150305.29

\begin{abstract}
Vipadikahara Grita Taila is specific and effective medicated oil, use externally to treat the "Vipadika" skin lesion. Vipadika is a common skin ailment in geographically warm country like Sri Lanka. Large fissures with number of cracks in feet and hands with severe pain are the symptoms of Vipadika skin lesion according to Ayurveda texts. Though Vipadikahara Grita Taila is an effective treatment, two important plants (Leptadenia reticulate and Berberis aristata) are not available in Sri Lanka to prepare this medicated oil. Therefore, as an alternative, substitute oil was prepared introducing two newly identified substitute plants (Wattakaka volubilis and Berberis ceylanica). Still, researches are not attempted to evaluate the efficacy of this substitute oil on Vipadika skin disease. The aim of this study was to evaluate the effectiveness of substitute oil on Vipadika skin lesion. A forty seven year old female house wife was presented to outpatient department (Kayachikitsa clinic), Ayurveda Teaching Hospital in 2014 with complaints of bilateral large cracks and fissures in feet since 05 years. According to clinical features of Ayurveda view, this case diagnosed as Vipadika skin lesion. To manage this, standardized substitute oil was applied over the affected area twice a day, in the morning and evening in dried feet after washing with Luke warm water for 6 weeks duration. The lesions progressively healed reducing with cardinal symptoms during the treatment period and gradually the skin of the feet became almost normal. Present study had proven that, substitute oil for Vipadikahara Grita Taila can be used externally as an effective medicated oil to manage Vipadika.
\end{abstract}

Keywords: Vipadikahara Grita Taila, Substitute Oil, Vipadika, A Case Study

\section{Introduction}

Skin is an outermost cover of the body, plays a chief role in maintaining barrier between internal and external environment. In addition, the healthy skin is the primary requirement for the beauty as well as having an attractive personality, which are the basic instincts of the human being. Any weakness at the skin becomes a great handicap for a person in the society, because it has a visible pathology. Vipadika dermatosis comes under eighteen subtypes of skin diseases in Ayurveda and it severely damaged the palms and feet of the person. Therefore, patients present with large fissures and cracks in their feet and palms (panipada sphuthana) with severe pain (tivra vedana) [1].

Ayurveda is the ancient health science and it has described the management of wound in detail. Many herbal formulations are being successfully used for wound healing since historical times. Pinda taila and Visarpahra taila are common examples for normally use medicinal formulations [2]. Animal studies also had proven the wound healing property of Vranashodhanahara taila and Doorvadi taila [3].

Vipadikahara Grita Taila (VHGT): medicated oil which was mentioned in Caraka Samhita [1] as a treatment for five types of skin diseases including Vipadika. Medicinal plants and other ingredients of the VHGT are Leptadenia reticulate 
(Family: Asclepiadaceae), Rubia cordifolia (Family: Rubiaceae), Berberis aristata (Family: Berberidaceae), Mallotus phillipinensis (Family: Euphorbiaceae) and Cow's milk, Bee's wax, Resin of Shorea robusta (Family: Dipterocarpeae). Sesame (oil of Sesamum indicum seeds, Family: Pedaliaceae) and cow's ghee were used as the base of the oil [4]. Though it is effective oil, two important plant materials are not locally available to prepare this medicated oil in Sri Lanka. Therefore, substitute oil was prepared using two newly identified medicinal plants; Wattakaka volubilis (Family: Asclepiadaceae) and Berberis ceylanica (Family: Berberidaceae) for Leptadenia reticulate and Berberis aristata in VHGT. Prepared substitute oil was standardized according to Indian Standard Methods of Sampling and Test for Oils and Fats [5]. The aim of this study was to evaluate the efficacy of substitute oil which may be used to Vipadika skin lesion for VHGT.

Forty seven year old female house wife was presented to outpatient department (Kayachikitsa clinic), Ayurveda Teaching Hospital in 2014 with complaints of bilateral large cracks and fissures in feet since 05 years. It starts from the site of the heels and gradually spread to the other part of the foot up to big toe. There are exacerbations and remissions during the past five years and she complained a severe pain throughout the day and night when it became worst. When the cracks are particularly bad, she felt fever and walking difficulty. Fissures, cracks and pain get worse with the foods mixed with salmon, toona fish and pickle, lime pickle, dry fish and vinegar added curries. Her vitals were stable with Height - $125 \mathrm{~cm}$, Weight - $45 \mathrm{~kg}$, B.P. - 110/90 mm of Hg. While taking allopathic medicine, some relief was present but it is not permanent. Therefore, she has decided to get Ayurveda treatment. Other than this skin problem, patient is in good health.

According to symptoms, this case demonstrated as a classical presentation of Vipadika skin disease. There is no family history of such skin lesions or any other type of skin diseases. Patient was free from the symptoms of Diabetes Mellitus, hypertension, and chronic lung disease, and malignancy, sensitivity reactions to the medicated oils and Vipadika with secondary infections. Further, patient did not use any topical steroid/s for a longer period.

\section{Methodology}

This study was conducted in Ayurveda Teaching Hospital, Borella, with the approval of ethical review committee of Institute of Indigenous Medicine, University of Colombo, Sri Lanka (Re. No: 12/06). Evaluation was based on the reduction of the cardinal symptoms and healing of wounds by measuring the length, width, depth and number of ulcers. Linear measurement: simple dimensional assessment was performed in cutting or splitting wounds using a polythene piece keeping on the foot / palm of the patient and marked them. Later, total lengths (in $\mathrm{mm}$ ) of the fissures were measured using plastic flexible ruler. Length is the longest distance of a wound, margin to margin. One or more than 1 cm lengthy fissure wounds were measured and calculated. Slight cracks were ignored. The second measurement (width) is made perpendicular to the length (also at the widest distance). When measuring the width (in $\mathrm{mm}$ ), placed the ruler over the widest aspect of the wound and measured from 3 o'clock to 9 o'clock according to Wendelken and coworkers [6]. When measuring depth placed a cotton-tip applicator into the deepest part of the wound bed. Then grasped the applicator by the wound margin and place it against the ruler and got the reading (in $\mathrm{mm}$ ) [7]. Further, photographs were taken before and after the treatment to confirm the healing. Scoring system was developed to evaluate cardinal symptoms: itching, roughness of the skin, pain, oedema, burning sensation at the affected site and dark shade in the affected site of the skin subjectively. Physical findings were evaluated day zero, during and after the treatment. In addition, General symptoms such as fever, lymph enlargement were also examined and evaluated before, during and after the treatment.

Assessment of cardinal symptoms were done with the help of Numerical Rating Scale and patient was advised to choose a number for grading to describe their current condition which was shown below.

Itching

No itching

Mild itching (only aware of itching when relaxing)

Moderate (sometime disturb the sleep and day time activity)

Severe (constant itching, frequent sleep disturbance) 3

Roughness of the affected site

Insignificant dryness at the foot/palms

Roughness is present when touching

Excessive roughness presents and leading to itching

Excessive roughness presents and leading to slight

cracks

Roughness leading to cracks

Pain

No pain

1

2

Mild pain of easily bearable nature, comes occasionally

Moderate pain, but no difficulty

Having frequently and requires some measures for relief

Pain requires medication and may remain throughout 4 the day

More difficulty: pain is severe, disturbing sleep and 5 requires analgesics

Oedema

No swelling

Slight swelling

Moderate swelling

Severe swelling

Burning sensation at the affected site

No burning sensation at the affected site

Mild burning sensation at the affected site but bearable

nature, comes occasionally

Moderate burning sensation at the affected site, but no difficulty

Burning present all over the day and requires some
3 
measures for relief (water. etc)

Requires some medical applications but may remain throughout the day

More difficulty and burning sensation is severe, disturbing sleep

Dark shade in affected part

No skin discoloration is present on the feet

Slight discoloration is present on the skin feet

Discoloration with slight skin cracks

Dark dirty color in the sole with large cracks

Patient was advised to apply the oil over the affected area twice a day: morning and evening in dried feet after washing with Luke warm water. A demonstration was conducted about application of the oil over the affected area at the beginning of the treatment. Treatment duration was 6 weeks and volume of the oil was $60 \mathrm{~mL}$ per week. Patient was advised not to apply any other remedy on the skin lesion or taking any internal medicine during the study period and also not to apply the trial drug on the day of assessment. Followup period was 03 months.

Statistical analysis: Data are given as means \pm S.E.M. Statistical comparisons were made using one-way ANOVA followed by Duncans multiple range test. A P value $\leq 0.05$ was considered as significant.

\section{Results and Discussion}

The lesion was cured during the treatment period and the skin of the feet became almost normal gradually at the end of the treatment as shown in Fig. 1, Fig. 2 and Fig. 3. The length, width, depth and the number of lesions were significantly reduced in $79.3 \%, 86.3 \%, 91.2 \%$ and $90.08 \%$ respectively. In addition, itching $(90.0 \%)$, roughness $(80.23 \%)$, pain $(97.07 \%)$, oedema $(98.55 \%)$, burning at the affected site (97.71\%) and dark shade (81.03\%) were significantly reduced in affected site with the treatment. Healing rate of fissures by this substitute oil is almost same as VHGT [8]. These healing properties may be due to same organoleptic properties and other phytochemicals of the substitute oil as in VHGT $[9,10]$. When preparing medicated oil, first dirt free plant materials were mixed with water and the mixture is heated using mild flame until the volume of water reduced to one fourth of the original volume. Substitute oil is rich in phenolic compounds, tannins, saponins, steroid glycosides and coumarin [9]. Due to the hot extraction technique, most of the chemical compounds have been extracted into the oil. Therefore, it possesses high medicinal value though it contains less number of medicinal plants.

The most important bioactive compounds of the medicinal plants are alkaloids, flavanoids and phenolic compounds [11]. Natural antioxidants mainly come from plants are in the form of phenolic compounds such as flavonoids, phenolic acids, etc. [12]. Phenolic compounds possess biological properties such as antiaging, anti-carcinogenic, antiinflammatory, cardiovascular protection and improvement of endothelial function, as well as cell proliferation activities [13]. Accordingly, phenolic compounds contain in substitute oil help to heal wounds in many ways such as analgesics, anti-inflammatory and antimicrobial activities. The alkaloids contained in plants are used in medicine as anaesthetic agents [14]. Further, phenolic compounds present in the substitute oil give more support to repair and recover the wound. Therefore, substitute oil can be used easily as a treatment for Vipadika skin lesion for VHGT.
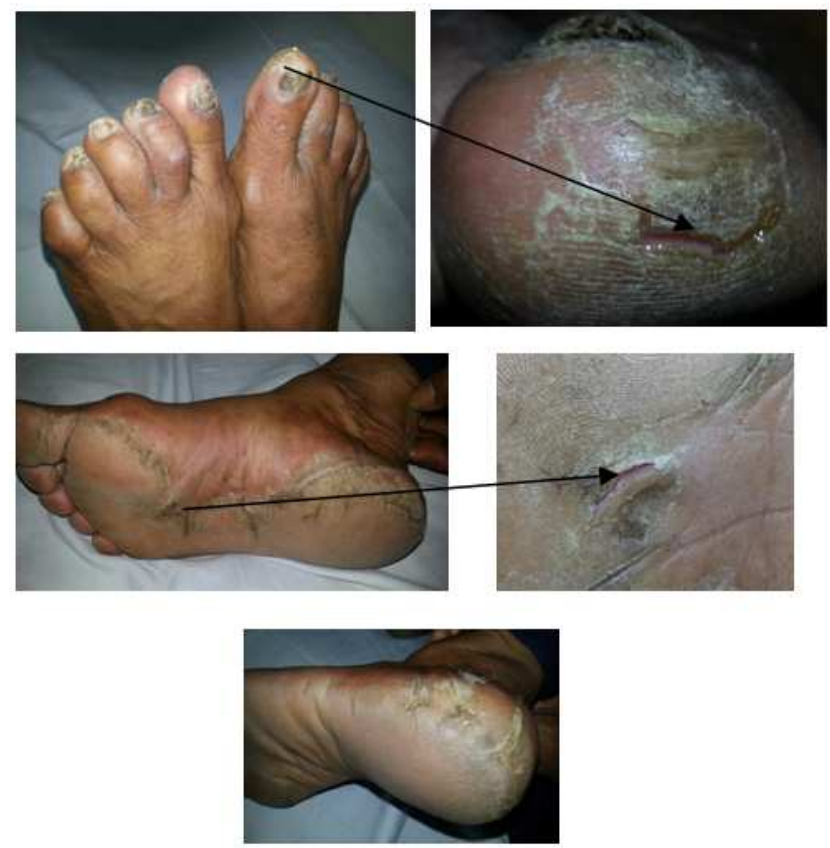

Fig. 1. Before Treatment for Vipadika skin lesion.
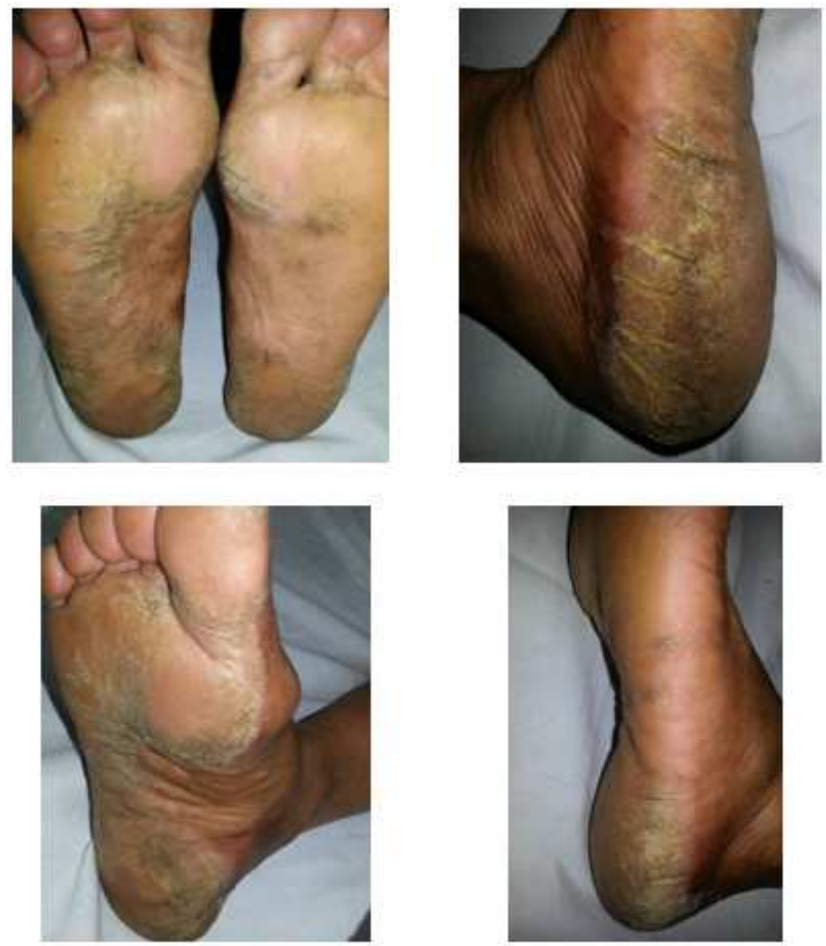

Fig. 2. After 3 weeks of treatment by Substitute oil. 

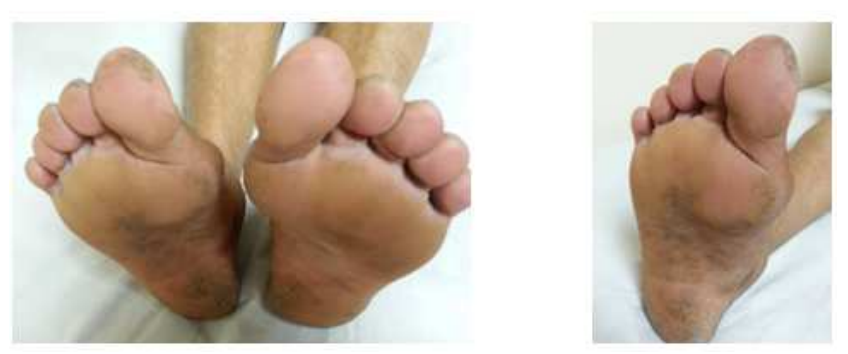

Fig. 3. After 6 weeks of treatment by Substitute oil.

\section{Conclusion}

Substitute oil facilitated wound healing and reduced the cardinal symptoms significantly. Accordingly, present study revealed that, the substitute oil can be used as an alternative to VHGT to manage the Vipadika skin lesion. Further therapeutic efficacy of the VHGT and the substitute oil is almost same.

\section{Acknowledgement}

National Centre for Advanced Studies for Humanities and Social Sciences, Ward Place, Colombo 7, Sri Lanka is acknowledged for providing financial assistance.

\section{References}

[1] Sengupta S., Sengupta S. B., (Eds.) Carakasamhita (Vol IIINidanasthana, Cikitsasthana), Chaukhambha Orientalia, Varanasi. 1991.

[2] Ayurveda Pharmacopoeia, Vol. 1, Part 1, Department of Ayurveda, Sri Lanka, 1976. pp. 243-259.

[3] Jain V., Naresh K. Kumawat K., Shankar R., Zafer K., Wound Healing Properties Of Vranashodhanahara Tail And Doorvadi Tail As An Experimental And Comparative Study On Albino Rats, International Journal of Ayurveda and Pharma Research, Int. J. Ayur. Pharma Res, 2015. 3(2) pp35-41.

[4] Senagupta N., (Ed). Caraka Samhita (Vol III- Cikitsasthana), Sri Rangalalaminnena press, India 1855.
[5] Indian Standard Methods of Sampling and Test for Oils and Fats, Part 1 Sampling, Physical and Chemical Tests. Bureau of Indian Standards. 1976.

[6] Wendelken E., Berg T., Lichtenstein P., Markowitz L., Comfort C., Alvarez M., Wounds Measured from Digital Photographs Using Photo-digital Planimetry Software: Validation and Rater Reliability, 2011. 23(9). pp267-275.

[7] Morgan N., http://woundcareadvisor.com/measuring-wounds, 2012 July.

[8] Hewageegana S., Arawwawala M., Dhammarathana, I., Ariyawansa S., Tissera M., Vipadikahara Grita Taila as a remedy for Vipadika skin disease: A case study, National conference on Indigenous systems of Medicine for $21^{\text {st }}$ Century, 2015. pp 91.

[9] Hewageegana S., Arawwawala M., Fernando P., Dhammarathana I., Ariyawansa S., Tissera M., Standardization of a Substitute Oil for Vipadikahara Grita Taila which Used for Skin Diseases, Pharmacologia, 2014.Vol. 5 Issue 1, pp 32-35.

[10] Hewageegana S., Arawwawala M., Fernando P., Dhammarathana I., Ariyawansa S., Tissera A., Standardization of Vipadikahara Grita Taila: an ayurvedic medicated oil for common skin lesions, Uni. J. of Ayu. Herb Med, 2013. 01 (01), pp 48-51.

[11] Devendra N., Srinivas N., Solman, S., A comparative pharmacological and phytochemical analysis of in vivo\& in vitro propagated Clotalaria species. Asian pacific J of tropical med. 2012. 5: pp 37-41.

[12] Ali S., Kasoju N., Luthra A., Singh A., Sharanabasava H., Sahuand A., Bora U., Indian Medicinal herbs as source of antioxidants. Food Research International, 2008.41, 1-15.

[13] Han X., Shen T., Lou H. Dietry polyphenols and their biological significance. Int. J of Molecular Sci, 2007. 8, pp 950-988.

[14] Herourat D., Sangwin S., Finiaux A., Sangwan-Norrell, S., Variations in the leaf alkaloid content of androgenic diploid plants of Daturu innoxia, Planta medical. J of Medicinal Plants Res, 1988.54, pp 14-20. 